\title{
Monsters and posttraumatic stress: an experiential-processing model of monster imagery in psychological therapy, film and television
}

\author{
Jenny Hamilton (iD ${ }^{1 凶}$
}

Trauma survivors may see images of monsters in nightmares and visions when experiencing posttraumatic stress. However, there has been little commentary on the significance and meaning of this imagery and the wider relationship between monster imagery and posttraumatic stress. Applying an integrated experiential-processing approach to working with trauma in Counselling and Psychotherapy, emphasis is placed on facilitating 'processing' or making sense of the trauma, psychologically, emotionally, existentially and culturally. Examining the interplay of these elements, this paper explores monsters as symbol and metaphor for unspoken or unprocessed personal and cultural trauma, vessels for symbolically representing underlying, unacknowledged fears and experience. This paper discusses how encounters with the monster onscreen, in mental imagery or metaphor, may be allegorical to the individual's internal struggle with post-traumatic stress. The model presented is applied within an analysis of the symbolic representation of the trauma of cancer, cancer treatment and traumatic loss in survival horror movie The Shallows (Collet-Serra (dir) (2016). The Shallows. Columbia Pictures). Jungian ideas are integrated to consider monsters as emergent symbolisation of unspoken 'shadow' fears, such as those surrounding cancer. In an experientialprocessing account of trauma, incongruence between self-concept (our beliefs about self and world) and our actual experience of traumatic events is viewed as a source of psychological distress, prompting a breakdown and reorganisation of the self-structure. It is proposed that trauma experience confronts us with our mortality and fragility, bringing us into contact with the sense of 'abject' horror represented by monster imagery. Creeds (2007. The monstrous feminine: film, feminism, psychoanalysis. Routledge, London and New York) description of the abject as the 'place where meaning collapses' is applied to an understanding of psychological trauma, given that encounters with existential threats may render the everyday meaningless, engendering a need for meaning-making. Monster imagery psychologically represents the collapsing border between our ideas about self and world, and the destabilising experience of the shattering of pre-trauma assumptions. In this account monsters are located within a wider, adaptive evolutionary drive towards the reduction of trauma-related psychological distress, through symbolising experience into awareness for processing and meaning making. In this way monsters may play a complex role in a human struggle to come to terms with overwhelming events.

\footnotetext{
${ }^{1}$ Bishop Grosseteste University, Lincoln, UK. ${ }^{凶}$ email: Jennifer.hamilton@bishopg.ac.uk
} 


\section{Introduction}

'When we cannot find a way of telling our story, our story tells us-we dream these stories, we develop symptoms, or we find ourselves acting in ways we don't understand' (Grosz, 2019, pp. 12-13).

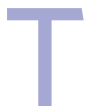

his paper explores the relationship between monsters and posttraumatic stress, informed by themes I noticed emerging from my therapeutic work as a counsellor with trauma survivors and a wider review of relevant literature. Trauma survivors may encounter imaged representations of traumatic experience as monstrous or shadowy figures that encapsulate their sense of fear or terror, within their nightmares, intrusive mental imagery or hallucinations (Cushway and Sewell, 1992; Prouty, 2007; Cooke, 2017; Hamilton and Sullivan, 2015). They may experience the self as monstrous in some way, for example, feeling oneself to be 'possessed' by 'demons', and psychosis can have an aetiology in psychological trauma (Cooke, 2017). Monsters can be used metaphorically by survivors to describe their experience. Imaged representations of fear states such as hallucinations may present a direct representation of the trauma. For example, an abuse survivor may see their abuser sitting next to them. In other cases, the experience is a symbolic representation, perhaps seeing a monstrous or shadowy figure, or hearing a scary voice. Monster imagery is a feature of art therapy, particularly in work with children who have experienced traumatic events (Clements, 1996; Kozlowska and Hanney, 2001; Lieberman, 2007). Additionally, Blake (2012) noted that the 'wound obsessed' genre of cinematic horror may be representative of the "Wounds of Nations", from cultural or historical trauma related to war or genocide.

Considering these experiences, I propose an experientialprocessing model of monster imagery, viewed here as an initial, symbolic emergence of traumatic experience into awareness. I argue that monster imagery may present an opportunity to face, process and piece together fragmented traumatic experience; a function of an adaptive self-actualising drive towards growth and psychological homoeostasis. In an experiential-processing account, incongruence between self-concept (our beliefs about self and world) and actual experience is viewed as a source of psychological distress. Processing, making sense of, and accepting, even distressing experiences, into awareness, may reduce psychological distress by enabling us to be more at ease with ourselves and become more of a 'healthy whole', psychologically and emotionally (Rogers, 1951). Traumatic events necessitate a break down and reorganisation of the self-structure, to integrate experience 'incongruent' with our perceptions of self and world. My analysis will draw parallels between this experiential processing account and the idea of monsters as symbolic of the 'abject' (Creed, 2007), whose psychological terror lies in symbolically representing the collapsing boundary between the subject, constructed through language, and conflicting experience. I integrate Jungian ideas that monster imagery and metaphors emerge from our disowned shadow feelings, that may need to be faced, owned and integrated into the psyche for psychological wellbeing. Jungian development of psychodynamic ideas influenced humanistic psychology, associated with Rogers' body of work. It is included here as significant to understanding symbolic imaged representations and their role in integrating elements of the psyche. The model and analysis is underpinned by a Jungian understanding of the symbol; as an emergent, intuitive and evolving representation of experience (Stevens, 1994). The model developed in this paper is applied to analysis of the way cancer fears and traumatic grief are represented in survival horror The Shallows (Collet-Serra (dir), 2016). I argue that monsters play a complex role in our adaptive drive to integrate, process and make sense of traumatic experience, a key element of restoring psychological wellbeing in response to posttraumatic stress. In this paper, the term monster refers specifically to imaged representations of threat-based experience that may be monstrous depictions of real creatures (such as the shark in survival horror) or an imagined, dreamed or hallucinated fictional creature. The monster signifies 'something other than itself, a 'displacement' that 'inhabits the gap between the time of upheaval that created it and the moment into which it is received' (Cohen, 1996, p. 6). It symbolically gives 'form to fears, desires and anxieties, allowing the channelling and expulsion of emotional energies' (Botting, 2003, p. 341). Monsters may give form to difficult emotions, associated with trauma, and symbolise the displaced experience, fragmented memory and abject horror of traumatic events.

\section{Posttraumatic stress as an impediment to experiential- processing}

Experiential-processing is particularly important for therapeutic work with psychological trauma. The traumatic stress response can be so overwhelming it requires a more complex and nuanced process of sense-making and may impede processing. A diagnosis of posttraumatic stress disorder (PTSD) is usually given when difficult psychological experiences associated with the traumatic event persist beyond the initial aftermath of the traumatic event. Events typically classed as traumatic usually involve direct exposure to significant threat of harm to self or someone close. They may include war, disasters, physical and sexual assault, serious accidents, serious illness and some bereavements. Childhood trauma can result from prolonged exposure to adversity, neglect or abuse (van der Kolk, 2014) and attachment difficulties can be potentially traumatic for infants (Warner, 2005). Not everyone exposed to such events experiences PTSD and our response to events may more accurately indicate if we have experienced the event as traumatic (Levine, 1997).

The high level of threat presented during traumatic events can imprint memories of extreme danger very quickly to enable them to be accessed instantaneously for future survival (Rothschild, 2000; Brewin et al., 1989; Brown and Kulik, 1977). Traumatic memories can manifest as intense feelings, images or bodily sensations, flashbacks and intrusive thoughts. Posttraumatic stress can often be accompanied by feelings of detachment and a sense of 'unreality' of experience that my take on a distorted or dream-like quality. The long-term affects associated with trauma often manifest in these more implicit and unusual ways. The process of piecing together traumatic memories in trauma therapy can enable clients to process traumatic experience by attaching a sequential, narrative structure to the events (Rothschild, 2000). Traumatic events can shatter our assumptions that the world is a reasonably safe and stable place (Janoff-Bulman, $1985,1989,1992)$ leaving a profound sense of overwhelm that can work on many levels: existential, social, psychological and emotional. Survivors may struggle to comprehend their experience in a world that may not make sense to them anymore (Janoff-Bulman, 1985, 1989, 1992). The sense-making, verbalising, or 'processing' that is the work of trauma-informed psychological therapy is very much about putting all this back together into a coherent narrative or story. Personal stories may be more easily processed through connection with known narratives and literary archetypes (Jungian archetypes are recurring symbolic figures evident across cultures) available within wider culture and monsters are a recurring feature in folk tales, literature and film. Psychological therapy informed by an understanding of posttraumatic stress, pays attention to physical, psychological and emotional effects of trauma within the wider cultural context. 
A trusting relationship enables clients to talk about their trauma experiences, while techniques such as 'grounding', designed to deescalate the physiological stress response, aid in facilitating processing safely to avoid re-traumatisation (Rothschild, 2003). This piecing together and sense-making helps survivors to locate the trauma emotionally, psychologically, culturally and existentially within a wider life narrative that allows for a renewed sense of meaning and purpose in life.

\section{Trauma as the 'place where meaning collapses': experiential- processing and the abject}

Experiential-processing approaches relate to Rogers (1951) theory of personality development. Psychological distress is rooted in incongruence between our direct experience of the world, 'organismic experiencing', and the 'self-structure', our beliefs about self and world. The self-structure encapsulates our values, cultural and familial norms internalised from our upbringing, socialisation and wider culture. It is who we think we are and how we think the world is. We may deny incompatible experiences into awareness. Joseph (2017) applies this to an understanding of posttraumatic stress experiencing and the processing of trauma in therapy. He proposes that posttraumatic stress can be understood as the normal psychological manifestation of a process that is instigated when the self-structure comes under threat' (p. 235). Reintegration necessarily requires 'accurate symbolisation in awareness of experience' (p. 239). Increased incongruence, associated with trauma, can lead to increased anxiety and disorganisation during the breakdown and reorganisation of the self-structure, accounting for the intrusion and avoidance experiencing, characteristic of posttraumatic stress. The person attempts on the one hand to accurately symbolise in awareness their experience (intrusion) and, on the other, to deny their experiences and hold onto their pre-existing self-structure (avoidance)' (p. 238). Incongruence can occur even if the experience is anticipated. For example, soldiers trained for battle may still find the actual experience of war incongruent with the values and assumptions that comprise their self-structure. Exposure to the traumatic event, through narrating it within a safe and accepting therapeutic relationship is a cornerstone of contemporary trauma therapy (Joseph, 2017; Rothschild, 2003), and a fundamental element of Rogerian-based experiential-processing approaches to therapy, that enable the integration of self and experience.

In her analysis of horror from a psychoanalytic feminist perspective, Creed (2007) develops Kristeva's (1982) rethinking of the sociological concept of 'abjection' applied to an analysis of female monstrosity. Creed $(2007$, p. 8 ) discusses the abject in the context of monstrosity, as that which relates to the border that separates the 'the human and non-human and the fully constituted subject from the partially formed subject'. Creed's (2007) development of Kristeva's work is of particular significance to this analysis defining the abject as 'the 'place where meaning collapses', the place where 'I' am not' (p. 9). The abject must be 'radically excluded' from the subject to 'the other side of an imaginary border which separates the self from that which threatens the self.' (p. 9) She explains:

\begin{abstract}
'Abject things are those that that highlight the 'fragility of the law'...that exist on the other side of the border which separates out the living subject from that which threatens its extinction... The subject, constructed in/through language, through a desire for meaning, is also spoken by the abject, the place of meaninglessness' or the 'place where meaning collapses'. The subject desires the abject but must be repelled for fear of 'self annilation" (p. 10)
\end{abstract}

This is particularly relevant to horror, a genre centred greatly on death and the undead, where the corpse is 'utterly abject' as a 'body without a soul' (Creed, 2007, p. 10) at the boundary between life and death, and presenting a religious taboo (examples include vampires, zombies and robots, along with monsters such as werewolves that transgress the human/animal boundaries).

Applying this to an experiential processing account of trauma I propose that the self-structure is analogous to the subject, constructed through language and culture, and our actual organismic experiencing of the world analogous to the abject; that which may challenge perceptions of self and world. In this way trauma experience is abject. Trauma confronts us with our mortality, it is the place where meaning collapses, it emphasises the fragile boundary between life and death, safety and impermanence, health and illness, good and evil, the human and inhuman. The drive to process and make sense of experience following trauma, is akin to the need for the subject to make meaning as a matter of survival, it is a refuge from the meaninglessness of seemingly random or brutal events. Traumatic events can engender a need to find new meaning and purpose in the aftermath of encounters with existential threats, that may render the everyday meaningless. In post-traumatic stress, monster imagery sits at the border between our ideas about self and world and our new experience of the shattering of these assumptions.

\section{Trauma and monster imagery}

In his experiential-processing account, Prouty (2007) considers the hallucinatory image as the initial symbolic emergence of experience into the individual's awareness, that relates back to a real traumatic event. He observed in case examples that hallucinations are simultaneously experienced as real, while symbolising traumatic events from the past; they are both 'phenomenological' and 'symbolic' (p. 172). Applying the idea that 'Symbols are experiences that mean or refer to other experiences' the hallucination is 'an expressive transformation of real-life experience into image-form' (p. 171). One client describes how 'The images start in my unconscious and move towards my consciousness to be real' (p. 171).

Prouty (2007) discusses an example of therapeutic work with an adult who hallucinates a 'purple demon' (p. 172). During therapy the hallucination processes back to traumatic experience from childhood of being hit by the teacher in response to his learning difficulties. The client describes an 'evil thing' emerging, firstly as a purple picture that 'wants the past to come back' (p. 173). Prouty makes statements that closely reflect the clients emergent experience as it unfolds, such as: 'It's a dark purple picture and you don't like it'; and 'It's evil and it's in the past' (p. 73). The client's hallucination transforms from a 'purple demonic image' to an orange square that 'makes noises' and hates him (p. 175), then into a 'pretty, mean and scary lady' with 'dragon eyes' (p. 177) and finally becomes recognisable as his teacher. The imaged symbolisation of the trauma experience is processed so that the client becomes fully aware of the real experience to which it relates. The hallucination is transformed into a coherent memory and given meaning. Applying this understanding to Cohen's (1996) cultural analysis, the monster image at once symbolises the displacement of trauma experience at the time of the event, and the re-emergence of this experience into awareness. Indeed, the monsters 'undead' qualities and unexpected recurring attacks may be symbolic of post-traumatic stress experiencing itself, reflecting associated recurring symptoms such as intrusive thoughts, flashbacks or intrusive mental imagery. Facing and defeating Monsters in fiction, may be analogous of the process of overcoming trauma within therapy, which often necessitates a level of re-exposure to trauma experience for integration of the experience to occur. 
Kozlowska and Hanney (2001, p. 51) and Crittenden (1997), note that prior to developing language, memories may be 'imaged' as infant's experience 'perceptual sensory images of the contexts associated with safety or danger, such as sounds, darkness, smells, visual images and bodily states'. Clients may experience difficulty verbalising affective states in trauma therapy, and art therapy may better capture these early memories, stored and remembered as images. The 'non-verbal medium' of art can enable us to access and visually express imaged memories, symbolic of experience, allowing 'exposure to conscious reflection and cortical processing' and emergent images can be used therapeutically to symbolise and process trauma towards 'adaptive integration' of experience (Kozlowska and Hanney, 2001, p. 52). Clements (1996) noted monsters (or grotesque figures) frequently present in art therapy with children as metaphors to describe trauma or abusive adults (Kozlowska and Hanney, 2001, p. 52). Art can provide a 'transitional space' to 'externalise' a concrete representation of trauma experience and discussion of artwork can enable meaning and sequence to be attached through constructing a narrative. Indirect exposure to experience through symbolisation permits 'anxiety to be tolerated and the unspeakable and unthinkable to be contemplated' (Kozlowska and Hanney, 2001, p. 53). Symbolic imagery of trauma experience can in this way provide a more tolerable way to represent, process and integrate experience.

Building on this, Fig. 1 articulates the idea of monster imagery as an initial symbolic emergence of trauma experience into the self-structure within an experiential-processing model. Rogers (1951) notes that we are less likely to experience psychological distress when we are continually in a fluid process of integrating experience but are more likely to experience difficulty if our selfstructure becomes fixed or ridged, leading to high levels of incongruence.

Figure 1 articulates the emergence and processing of internal mental imagery, encountered in dreams, hallucinations, intrusive mental imagery, art therapy and use of metaphor in dialogue. It also presents interesting possibilities for monster imagery in therapy, film and television as an initial, symbolic representation or emergence into awareness of traumatic experiencing, both individually and culturally. Rather than simply an unpleasant or undesirable manifestation of fear, if approached in a safe and therapeutic manner, monsters may present an important opportunity to face and process difficult feelings and traumatic experience into awareness. They may represent the organism's adaptive actualising tendency to move towards growth, in presenting difficult material into awareness that, although initially distressing, may ultimately reduce incongruence between self and experience.

\section{Trauma and the cinematic monster}

'A camera always looks both ways' (Patterson, 1996).

Asma (2009) charts the development of monsters from toothed and clawed creatures in Greek mythology representing evolutionary survival fears, through to psychological horror, perhaps more reflective of modern and post-modern existential angst. Onscreen encounters with the cinematic monster may be allegorical to the individual's internal struggle with post-traumatic stress; the survivor has to struggle with repeated, unexpected, intrusive trauma symptoms that must be overcome to restore equilibrium, allegorical to the cinematic monsters unexpected appearance and the ensuing battle to destroy it. Cinematic Monsters may represent fears in a tangible way, presenting a metaphor that 'gets up and walks' (Moretti, 1982). Seeing the monster destroyed may enable us to face our fears and survive.
Levine (1997, p. 155) discusses how trauma survivors experience a perpetual sense of a 'threat that can't be found'. The physiological state of hyperarousal, experienced in response to the actual threat, becomes a state of hypervigilance during post-traumatic stress; a sense of perpetual anxiety where survivors scan for external threats in response to this internal feeling of anxiety. Similarly, Heriot-Maitland et al. (2019, pp. 2-3) view voicehearing as "disowned" threat-based representations of the self, rooted in childhood trauma. I propose that identifying this threat as a monster and seeing it vanquished on screen may reflect this process of scanning for threats to focus and assuage feelings of unspecified fear.

\section{Monsters, cancer and surviving traumatic loss}

'Medieval heroes had to slay their dragons; modern heroes have to take their dragons back home to integrate into their own personality.' (Johnson, 1991, p. 51).

Recent depictions of monsters symbolic of psychological trauma are evident in A Monster Calls (Ness et al., 2013) and shark attack survival horror, The Shallows (Collet-Serra (dir), 2016), where, respectively, a tree monster and monstrous shark are representative of the trauma of cancer, cancer treatment, grief and the premature loss of mother. This particular loss, and the trauma of witnessing the maternal body undergo a process of disease and death, can be perceived as a traumatic threat to survival relating to the prolonged dependency of human infants upon the primary caregiver. The loss of the maternal body, may give a traumatic sense of loss of one's own body. Genetics give a sense that mothers' death may present a foreshadowing of ones' own death. Our own mortality may be brought into existential awareness. While a rite of passage, we need to survive our parent's death as an expected part of life, for the young protagonists in these movies this loss occurs far sooner than expected, contributing to a lack of control and predictability and the loss of ones 'secure base' (Bowlby, 1961, 1980).

Considering abject representations of cancer fears and traumatic bereavement in The Shallows (Collet-Serra (dir), 2016), we may note the movies focus around female figures, Nancy and her mother. Creed (2007) considers representations of the monstrous-feminine' in horror; uniquely gendered constructs of female monstrosity rooted in patriarchal fears and stereotyped assumptions. She reconceptualises Freud's theory that men fear women as castrated other, identifying female monstrosity as related to a'fear of woman as a castrating other' (p. 6). In Creeds' analysis the monstrosity of the shark in movies such as Jaws, may relate to its' symbolic representation of the vagina with teeth, as shark attacks that sever symbolically phallic limbs evoke castration fears. However, I argue there may be more to consider here, as we see explicit themes of cancer, grief and the traumatic loss of mother set the scene for Nancy's battle with the shark. My intention in this analysis is to explore these representations of cancer trauma within the movie, integrating an experientialprocessing and Jungian analysis, where abjection has an integral role as a key element of trauma and horror. The analysis will include attention to Creeds (2007) consideration of the monstrous womb and Sontag's (1991) work on the development of cultural perceptions of cancer.

In my analysis I propose that the shark symbolism has particular relevance to cancer and cancer treatment. Sontag (1991, p. 60) discusses the way cancer and other illnesses have been used as metaphors for evil in society, as the 'horror' associated with it 'is imposed on other things'. Pertinent to shark symbolism, Sontag discusses descriptions of cancer as 'a process in which the body was consumed' (p. 11). Cancer itself is monstrous, and the 


\section{Monster Imagery}

Symbolic initial emergence of trauma experience. Monster imagery emerges from the interplay of phenemological trauma experience, 'imaged memories' of sensory experience, and the symbolic meaning assigned to monsters individually and culturally.

\section{Experiential processing}

Emotional, psychological and somatic processing of trauma experience via processing of monster symbolism into awareness.

Making sense of the monster imagery, in the wider context of the persons life, cultural context and belief system.

Fig. 1 The role of Monster imagery in the experiential processing of psychological trauma. Panel 1: Trauma experience emerges into awareness as monster imagery. Panel 2: Processing and making sense of the image and experience. Panel 3: Psychological integration of experience into the self structure.

shark symbolic of cancer as a biological, unemotional killer, a formidable and persistent enemy lurking beneath the surface of the body that requires a torturous, herculean struggle to fight and survive. The shark, in the movie becomes an abject representation of cancer. Both represent the boundary between life and death; between a healthy intact body and capacity for body injury (through shark attack or surgery); and the boundary between the instinct-driven, biological reality of nature and illness, in contrast to Nancy's thinking, feeling humanity. This struggle is particularly evident in Nancy's characterisation as a medical student, deskilled in the face of incurable cancer, unable to save her mother. The struggle at the abject boundary in the movie may represent processing traumatic experience emerging in the brains limbic system, linked to visceral grief and trauma experience (abject organismic experiencing), into the pre-frontal cortex, associated with our sense of self-constructed through language and socialisation (the self-structure or subject). The collapsing boundary needs to breakdown and change to integrate the overwhelming experience of trauma and loss during the reorganisation of the self-structure, allowing more visceral, organismic experience fully into awareness. The shark's monstrosity lies perhaps ultimately in the symbolic representation of unexpected, untimely death, serving as a traumatic reminder that illness and death can strike at any time, forcing us to confront our own mortality. It is reminiscent of the shattering of assumptions about self and world, associated with trauma, disrupting our sense of safety and integrity. Repeated unexpected attacks are reminiscent psychologically of the return of trauma experience via flashbacks, intrusive imagery, nightmares, and affective states such as a sense of anxiety or foreboding, characteristic of posttraumatic stress.

Successive shark attacks on the body and the ensuing struggle for physical survival, are allegorical to the body as the site of trauma in cancer, cancer treatment and subsequent cancer recurrences. This is particularly pervasive in the death of mother given the links between the maternal body and one's own, alongside possibilities for genetic hereditability of cancer. Sontag (1991) discusses the embattled language of cancer and cancer treatment with 'the patient's body considered to be under attack ('invasion') the only treatment is counter attack' (p. 65). The fight back is fraught with its' own horrors, as the gruelling nature of many cancer treatments lead to the perception that 'the treatment is worse than the disease' (p. 65). Nancy's battle with the shark is symbolic of a processing of the trauma of cancer, cancer treatment and traumatic grief.

Nancy visits an excluded island to surf the waters off shore of the beach that her mother visited while pregnant with her. She has dropped out of med school, experiencing a loss of meaning and purpose, following her mother's death. We see phone pictures of her mother in hospital, and she speaks of her mother in the past tense. There is a small land configuration off shore she nicknames the pregnant lady because of its shape, that forms the backdrop for the movie. The earth and sea are associated with the mother archetype (Jung, 1991) and this imagery gives a sense of Nancy's mother maintaining a kind of absent presence throughout the film, a feature of grief. The shark's abject role, representing the boundary between life and death, lies at the heart of its monstrosity. Sontag (1991) notes the sense of cancer as a growth within the body, rendering it 'pregnant with death', the shark represents cancer and death within in the maternal body that gave Nancy life. In the movie we see a lot of womb and birth imagery with Nancy surrounded by water, and the water infused with blood as the shark attacks. This is further evident in the wound created by the attack, as Kristeva (1982, p. 101) considers the image of birth as a 'violent act', fraught with blood and bodily fluids that Creed (2007) notes 'tears at the mother's skin and transforms her body into an open wound' (p. 48). In this way the waters surrounding the shape of the pregnant lady in the background become a kind of 'monstrous womb' for Nancy, a term used by Creed to articulate a feature of horror, centred around the construction of women's maternal function as abject, in linking her to the animal world and to the great cycle of birth, decay and death. These links serve to remind us of 'mortality' and 'the fragility of the symbolic order' (Creed, 2007, p. 47) both central themes of grief and trauma that Nancy is symbolically struggling to come to terms with. Jung (1991) notes that negative associations with the mother archetype can be symbolised by death, 'deep water' and 'devouring' animals, including 'large fish' (p.82).

Creed (2007, pp. 11-12) extends Kristeva's (1982) discussion of the abject nature of the maternal body as one that is 'a site of conflicting desires'; the desire to become a 'separate subject' and the desire to remain 'in a blissful relationship with the mother'. The child both desires and fears separation. We may view Nancy's journey as one of facing her fears around loss and separation from her mother, presenting a kind of rebirth into independent adulthood. Applying a Jungian analysis Nancy has undertaken 
the 'hero's journey' (Neumann, 1970) towards individuation, through integrating different archetypal aspects of the psyche towards becoming more of a healthy whole. Jung proposed a 'shadow side' of our unconscious self, the opposite of the 'persona', a kind of false mask we present to the world to live up to the expectations of modern society (Stevens, 1994). We disown socially unacceptable feelings such as anger, aggressive tendencies, fear, shame and our sense of our own inadequacies into the'shadow side' of our psyche. Contemporary depictions of cancer patients as brave, can carry a weight of expectation, leaving fears surrounding cancer banished or unspoken, only to reemerge as posttraumatic stress and anxiety, during grief or postrecovery. Applying a Jungian framework, monsters may symbolise displaced, disowned and disliked elements of our psyche, that we must confront. The task in Jungian psychotherapy is to own and re-integrate shadow feelings into the psyche. Jung (1991) notes that while we have a sense of a coherent self, and 'prefer to be always "I"... we are confronted with that inner friend or foe, and whether he is friend or foe depends on ourselves' (p. 131). Relating this to the model proposed in this paper, I view this narrative journey in The Shallows, as one allegorical to processing traumatic cancer experience into awareness through a symbolic struggle to confront and integrate associated shadow feelings. Grief emerges from love, and the shark symbolises the shadow side of love, the unbearable feelings attached to love and loss. In grief we might want to be brave, strong and stoic, but are actually experiencing intense, messy and less socially acceptable feelings such as anger, anxiety or depression; the shadow side of love. Pertinent to understanding links with the symbolism of a shark attack, the shadow is often represented archetypally as an 'enemy' or predator' (Stevens, 1994). We may also disown our competence and resilience into our shadow during traumatic loss, as we may feel overwhelmed or helpless. Through her confrontation with the shark, Nancy reconnects with her capabilities and personal agency.

Neumann (1970) articulates the stages of psychic development in Jungian thought, consolidating Jung's ideas into the stages of the 'hero's journey', ubiquitous in stories and mythology throughout history. This symbolises a male adolescent rite of passage towards maturity, via undertaking a journey and encountering adversity to win treasures and marriage. The hero encounters and is swallowed by a dragon, fighting his way out, symbolic of separating from the mother and rebirth into adulthood. In Nancy we see a contemporary female hero, forced to undertake the journey of separation from mother, as the shark attacks evoke this symbolic battle with the dragon and the feelings associated with this loss. The hero represents in the first instance, the ego-consciousness in Jungian theory; the organising, rational part of the psyche that keeps us functioning, but completing the journey is allegorical to a process of psychic integration within the whole Self (individuation). In trauma theory, the ego may represent the processing of experience into the cerebral cortex, the centre in the brain associated with reason, executive functioning and long term planning, from the brain's limbic system, associated with more visceral and instinctual trauma and grief feelings, that we may relate to the shadow.

Jung viewed symptoms as symbolic communications from the unconscious that the individuation process has become stuck. He discussed a creative function of illness, that can facilitate individuation as part of the compensatory function of the psyche as a self-regulating system seeking homoeostatic balance (Stevens, 1994). The Hero's' journey undertaken by Nancy is one towards the processing or integrating of her traumatic grief experience. Day (2012) notes that in the book A Monster Calls, the monster guides Connor, a boy dealing with his mother's terminal cancer, through Kubler-Ross's (1969) famous stages of grief, denial, anger, bargaining, depression and acceptance, now etched into the public psyche. I note that Nancy also goes through the stages of grief through her battle with the shark, itself a shadowy figure lurking under the surface that becomes more visible throughout the movie as Nancy faces and feels more of the difficult feelings associated with grief and trauma. It only emerges into the light towards the end when Nancy, is further along her allegorical journey of integrating shadow grief and trauma feelings. In both of these works, the word cancer is never spoken and in The Shallows it is never overtly stated that Nancy's mother has died. Sontag (1991, p. 7) discusses how the word cancer is often unspoken, conjuring up a sense of dread, viewed as an incurable 'evil, invincible predator' linked inextricably to death (and the modern tendency towards denial of death). The monsters in these works can be said to both symbolise and guide the young protagonists through shadow feelings surrounding cancer trauma, metaphorically representing the element of the psyche that holds banished, unspoken and socially unacceptable 'unspeakable' feelings.

We can identify Kubler Ross's stages of grief as a feature of Nancy's journey in The Shallows. Nancy's battle to survive a shark attack is foreshadowed by a broken surf board washing up on the beach at the beginning of the movie. Contrasted with subsequent scenes of Nancy arriving at the beach, denial is evident as Nancy seems like a tourist, visiting a picturesque beach, oblivious to any danger. Phone conversations reveal detachment from her family, evoking the isolation that is a common feature of grief. Later, stranded and wounded on a rock at sea, she bargains with a man on the shore who steals her belongings, he can keep it all if he will just call for help. The bargain fails and the man is killed. Depression is evident as Nancy spends the night alone at sea. Everyone who tries to save her is killed by the shark. She has a dark night of the soul, symbolic of the loneliness of grief and the idea that one has to work through those feelings for oneself. A wounded seagull keeps her company on the rock, a light figure in contrast to the sharks' dark underwater shadow. Later, Nancy heals the seagull, symbolic of her reconnection with the possibility of healing and with her own drive for survival. Her own leg seriously wounded, in Jungian terms Nancy assumes the role of the 'wounded healer', an archetype evident in Greek mythology. In attempting to cure his own incurable wound inflicted by Hercules arrow (Larisey, 2012), the centaur Chiron becomes a skilled healer, here perhaps reminiscent of the incurable wound of grief. Jung (1963) drew upon this myth to theorise that therapists who examine wounds within their own psyche can better address their patient's issues. The seagull fulfils a further aspect of the hero's journey, that the hero usually has a guide, a supernatural figure or a figure in nature, one example being Arthur and Merlin. Nancy has both the shark and the seagull as guides. In the figure of the shark, Nancy faces her darker shadow feelings and the seagull symbolises lighter feelings that she has lost touch with or disowned into the shadow, such as hope, resilience and her belief in her capacity for healing.

Nancy's anger emerges during her final showdown with the shark, wounded by its earlier attack and having endured a prolonged ordeal at sea. Nancy swears at the shark, stabs it, shoots it, sets fire to it and eventually kills it to survive. She leaves the safety of a floating buoy, plunges the depths of the ocean and faces the shark in the water, showing a move towards acceptance that she has to face the depths of her shadow feelings in order to survive. It is only by doing this that Nancy is able to destroy the shark and return to the shore. Washed up on the beach Nancy sees a vision of her mother as an angelic, ethereal, light figure. She has come through the shadow feelings, the shadow side of love, back into the the light of maternal love. Jung (1991) associated the sea with the unconscious, and discussed fish as symbolic of our 
evolutionary origins in the animal world linked to less conscious shadow feelings. As a food source, fish symbolise how the unconscious nourishes consciousness. The shark symbolically feeds traumatic experience into conscious awareness. Jung discusses Island symbolism as a point where land above water, symbolic of consciousness, and the 'murky depths' of the unconscious (the sea) meet, symbolising enlightenment and the higher Self. The recurring absent presence of Nancy's mother, her symbolic representation via the Island imagery, and her appearance as a transcendent figure, represent the Self, which for Jung is our core being, the reconciling whole that encompasses the psyche. The Self appears following psychic integration, as a transcendent figure that symbolises 'wholeness', a completion of a cycle of 'individuation', towards becoming psychologically integrated through 'inner transformation and rebirth' (Jung, 2019, p. 131). Nancy's symbolic rebirth indicates that she has completed a process of psychological integration and has become more of a whole Self. Here the renewed whole Self is analogous to the experience of post traumatic growth (PTG), that brings a sense of vitality, connectedness and purpose. Kintsugi, the Japanese art of mending broken pottery by pouring gold resin in the cracks, provides a useful metaphor for PTG. Broken pottery obtains a newly unique beauty and value; reflecting appreciation of cycles of impermanence and renewal. Similarly, the hero's journey ends with transformation and deification, here symbolised through Nancy's mother's manifestation as a transcended figure. In the final scene Nancy, now a doctor, achieves growth and deification in the eyes of her family, earning the admiration of her sister and her father's assurance that her mother would be proud.

In coming to terms with the abject horrors and body trauma of cancer and the traumatic loss of mother, Nancy must face up to, process and endure her traumatic grief towards becoming a more individuated Self. In an experiential-processing account, individuation is analogous to the process of self-actualisation (Maslow, 1998), where integrating more of our lived organismic experiencing into our awareness enables us to be more psychologically at ease with ourselves, and to fulfil more of our human potential (Rogers, 1951). The shark-as-monster, emerging from the depths, can be viewed as the initial symbolisation of trauma, grief and fear, into individual and cultural awareness. Nancy's battle with the shark is symbolic of the integration of difficult psychic experience, necessitating the collapse and reconfiguration of the abject boundary between self-concept and visceral organismic experience. The shark symbolises underlying, 'unspoken' and culturally 'unspeakable' fears surrounding cancer and death. Through facing the shark, Nancy and the cinematic audience may face these fears and survive.

\section{Conclusions}

This paper proposes an experiential-processing model, conceptualising the relationship between monster imagery and posttraumatic stress as the initial symbolic emergence into awareness of real traumatic experience. Monsters represent the abject terror presented by the collapsing boundary between the sense of a stable self and world, and contrasting traumatic experience of existential threat, horrific acts, illness, injury, moral injury and the precarious line between life and death. The capacity to develop initial, imaged representations of sensory experience may be based in the preverbal stage of infant development, where sensory experience of the environment, including that relating to safety and danger, is stored as 'imaged' memories (Crittenden, 1997). The ability to quickly imprint memories and initiate reactions relating to dangerous situations is advantageous to our evolutionary survival, but extremely distressing or overwhelming experience can reemerge as posttraumatic stress via intrusive thoughts, intrusive mental images, flashbacks, hallucinations and intrusive emotional or physical affective states (such as anger, anxiety, hypervigilance). Monster imagery can often be part of this experiencing, emerging in the dreams, art therapy images, mental imagery and hallucinations of trauma survivors or as metaphor within the therapeutic dialogue. The model presented in Fig. 1 proposes that monsters present a symbolic representation of the traumatic experience, informed by the interplay of the cultural and personal meanings the individual attaches to monster imagery. Onscreen monsters may represent the unspeakable terror of traumatic experiences associated with experiences such as war, abuse, terminal illness or traumatic loss, often otherwise unspoken in our society, presenting initial, symbolic representations of this trauma into our cultural awareness.

The model presented in this paper is underpinned by the idea that humans have a tendency towards sense making and 'processing' of experience into full awareness that is advantageous to their evolutionary survival. Warner (2005) applies Tooby and Cosmides (1992) evolutionary perspective to understand our drive towards experiential processing and our tendency to experience psychological distress when this is inhibited. Developing a complex and nuanced understanding of our physical and social environment through a process of sense-making is an adaptation of some evolutionary advantage, to escape predators and remain within the beneficial environment of our social grouping. I extend this to an experiential-processing understanding of post-traumatic stress, noting that trauma presents us with experience so overwhelming that it can severely inhibit our capacity for processing (see also Hamilton, 2013). If capacity for processing is impaired, this in itself may become a source of psychological distress (Warner, 2005). Traumatic events can shatter our assumptions about self and world, presenting a need for personal sense-making and meaning making, culturally, psychologically, emotionally and existentially. Processing traumatic experience into awareness, while initially distressing, tends to reduce psychological distress and lessen trauma-related symptoms. This process is evident in trauma-informed therapy, where clients attach a coherent narrative to their trauma experience, processing it emotionally and psychologically, while learning to understand and manage associated intrusive psychological, emotional and physical affective states within a supportive therapeutic relationship.

In an experiential-processing account monsters can be viewed as part of an adaptive drive within the human organism towards the reduction of trauma-related psychological distress, through presenting symbolic 'imaged' representations of experience for emotional processing and psychological integration. This aligns with a broader 'actualising' tendency, an instinctive drive towards growth, development, individuation and psychological homoeostasis. In this way such imagery may serve an adaptive function, allowing integration of difficult experience in the face of adversity. This understanding of monster imagery can be usefully applied in trauma-informed psychological therapy, if accompanied by attention to safe trauma practice, informed by practitioner awareness of the possibility for re-traumatisation for survivors who report engaging with horror movies (Wooder, 2008) and of the possibility of addiction to trauma (see van der Kolk, 1989). Monsters can be said to symbolise elements of human experience and of the human psyche, beginning a process of understanding and integrating this experience into self-awareness. Monsters show us something of what it means to be human, playing a complex role in the process of survival and adaptation, in the struggle to come to terms with existential threats and overwhelming events.

Received: 29 November 2019; Accepted: 14 October 2020; Published online: 05 November 2020 


\section{References}

Asma ST (2009) On monsters: an unnatural history of our worst fears. Oxford University Press, Oxford

Blake L (2012) The wounds of nations: horror cinema, historical trauma and national identity. Manchester University Press, Manchester

Botting F (2003) Metaphors and monsters. J Cult Res 7.4:339-365

Bowlby J (1961) Processes of mourning. Int J Psychoanal 42:317-39

Bowlby J (1980) Attachment and loss. Loss sadness and depression, vol. 3. Hogarth Press, London, England

Brown R, Kulik J (1977) Flashbulb memories. Cognition 5:73-99

Brewin CR, MacCarthy B, Furnham A (1989) Social support in the face of adversity: the role of cognitive appraisal. J Res Personal 23:354-372

Clements K (1996) The use of art therapy with abused children. Clin Child Psychol Psychiatry 1(2):181-198

Cohen JJ (ed) (1996) Monster theory: reading culture. University of Minnesota Press, Minneapolis

Collet-Serra J (dir) (2016) The shallows. Columbia Pictures.

Cooke A (ed) (2017) Understanding psychosis and schizophrenia: why people sometimes hear voices, believe things that others find strange or appear out of touch with reality, and what can help, revised ed. British Psychological Society. https://www.bps.org.uk/sites/www.bps.org.uk/files/Page\%20-\%20Files/Under standing\%20Psychosis\%20and\%20Schizophrenia.pdf. Accessed July 2019

Creed B (2007) The monstrous feminine: film, feminism, psychoanalysis. Routledge, London and New York

Crittenden PM (1997) Towards an integrative theory of trauma: a dynamicmaturational approach. In: Cicchetti D, Toth S (eds) The Rochester symposium on developmental psychopathology. Risk, trauma and mental processes. University of Rochester Press, Rohester, New York, pp. 34-84

Cushway D, Sewell R (1992) Counselling with dreams and nightmares. Sage, London

Day G (2012) Good grief: bereavement literature for young adults and a monster calls. Med Humanit 38(2):115-9

Grosz S (2019) Therapy. Penguin, London

Hamilton J (2013) Processing trauma: a case study: a psychosocial perspective. Dissertation, University of Nottingham.

Hamilton J, Sullivan J (2015) Horror in therapy: working creatively with horror and science fiction films in trauma therapy. Createspace

Heriot-Maitland C, McCarthy-Jones S, Longden E (2019) Compassion focussed approaches to working with distressing voices. Front Psychol 10(152):1-11

Janoff-Bulman R (1985) The aftermath of victimisation: rebuilding shattered assumptions. In: Figley CR (ed) Trauma and its wake, vol 1. Brunner/Mazel, New York

Janoff-Bulman R (1989) Assumptive worlds and the stress of traumatic events: Applications of the schema construct. Soc Cogn 7:113-136

Janoff-Bulman R (1992) Shattered assumptions: towards a new psychology of trauma. The Free Press, New York

Johnson RA (1991) Owning your own shadow: understanding the dark side of the psyche. Harpercollins

Joseph S (2017) Understanding post-traumatic stress from the person-centred perspective. In: Joseph S (ed.) The handbook of person-centred therapy and mental health. PCCS Books, Monmouth, pp. 233-224

Jung CG (1963) Memories, dreams, reflections. Pantheon Books, New York

Jung CG (1991) The archetypes and the collective unconscious. In: Read H, Fordham M, Adler G, Mcguire W (eds) The collected works of CG Jung, vol 9 Part 1, 2nd edn. Routledge, London

Kozlowska K, Hanney L (2001) An art therapy group for children traumatized by parental violence and separation. Clin Child Psychol Psychiatry 6(1):49-78

Kristeva J (1982) Powers of horror: an essay on abjection (trans: Roudiez LS). Columbia University Press, New York

Kubler-Ross E (1969) On death and dying. Macmillan, New York

Larisey KC (2012) The wounded healer: a jungian perspective. Available via Jung Society of Atlanta. http://www.jungatlanta.com/articles/fall12-woundedhealer.pdf. Accessed 15 July 2020

Levine PA (1997) Waking the tiger: healing trauma. North Atlantic Books, Berkley

Lieberman AF (2007) Ghosts and angels: intergenerational patterns. the transmission and treatment of the traumatic sequelae of domestic violence. Infant Mental Health J 28(4):42-439
Maslow AH (1998) Toward a psychology of being, 3rd edn. John Wiley \& Sons, New York

Moretti F (1982) The dialectic of fear. New Left Rev 136:67-85

Ness P, Kay J, Dowd S (2013) A monster calls. 1st U.S. paperback edn. Candlewick Press, Somerville

Neumann E (1970) The origins and history of consciousness. Princeton University Press

Patterson F (1996) Shadowlight-a photographers life. HarperCollins, Toronto

Prouty G (2007) The 'hallucination as the unconscious self. In: Worsley R, Joseph $S$ (eds) Person centred practice: case studies in positive psychology. PCCS Books, Ross-on-Wye, Herefordshire, pp 169-183

Rogers C (1951) Client centred therapy. Houghton Mifflin, Boston

Rothschild B (2000) The body remembers: the psychophysiology of trauma and trauma treatment. Norton, New York

Rothschild B (2003) The body remembers casebook-unifying methods and models in the treatment of trauma and PTSD. Norton, New York

Sontag S (1991) Illness as metaphor \& aids and its metaphors. Penguin

Stevens A (1994) Jung: a very short introduction. Oxford University Press, Oxford

Tooby J, Cosmides L (1992) The psychological foundations of culture. In: Barkow J, Cosmides L, Tooby J (eds) The adapted mind: evolutionary psychology and the generation of culture. Basic Books, New York, pp 19-136

van der Kolk BA (1989) The compulsion to repeat the trauma: re-enactment, revictimization, and masochism. Psychiatr Clin N Am 12 (2):389-411

van der Kolk B (2014) The body keeps the score: mind, brain and body in the transformation of trauma. Penguin

Warner MS (2005) A person-centred view of human nature, wellness, and psychopathology. In: Joseph S, Worsley R (eds) Person-centred psychopathology-a positive psychology of mental health. PCCS Books, Ross on Wye

Wooder B (2008) Movie therapy: how it changes lives. Rideau Lakes Publishing

\section{Acknowledgements}

The author wishes to acknowledge Dr. Caroline Horton and Dr. Judith Sullivan for support with proofreading.

\section{Competing interests}

The author declares no competing interests.

\section{Additional information}

Correspondence and requests for materials should be addressed to J.H.

Reprints and permission information is available at http://www.nature.com/reprints

Publisher's note Springer Nature remains neutral with regard to jurisdictional claims in published maps and institutional affiliations.

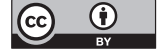

Open Access This article is licensed under a Creative Commons Attribution 4.0 International License, which permits use, sharing, adaptation, distribution and reproduction in any medium or format, as long as you give appropriate credit to the original author(s) and the source, provide a link to the Creative Commons license, and indicate if changes were made. The images or other third party material in this article are included in the article's Creative Commons license, unless indicated otherwise in a credit line to the material. If material is not included in the article's Creative Commons license and your intended use is not permitted by statutory regulation or exceeds the permitted use, you will need to obtain permission directly from the copyright holder. To view a copy of this license, visit http://creativecommons.org/ licenses/by/4.0/

(C) The Author(s) 2020 